\title{
PERANCANGAN DAN PENERAPAN METODE WEIGHTED PRODUCT DALAM SISTEM PENDUKUNG KEPUTUSAN PEMBELIAN LAPTOP
}

\author{
Nur Sumarsih \\ Program Studi Sistem Informasi \\ STMIK Nusa Mandiri \\ www.nusamandiri.ac.id \\ nursumarsih8@gmail.com
}

\begin{abstract}
Abstrak
Konsumen pada saat membeli laptop biasanya bertujuan sekedar mengerjakan pekerjaan sekolah atau kantor yang sebagian besar hanya untuk mengetik laporan atau mencari informasi lewat internet. Pasar di Indonesia sangat besar, sehingga berbagai merk dan jenis laptop yang tersedia saat ini dijual dengan harga yang bervariasi dan kompetitif, sehingga para calon pembeli menjadi tambah bingung untuk membeli. Kebanyakan para pembeli, membeli laptop dengan spesifikasi yang tidak disesuaikan dengan kegunaannya. Pendekatan yang digunakan untuk memecahkan masalah tersebut menggunakan metode Weighted Product. Penelitian ini bertujuan untuk membantu konsumen dalam pemilihan laptop melalui kriteria-kriteria yang telah ditentukan. Hasil perhitungan pemilihan laptop dengan metode weighted product yang didapat dengan hasil nilai tertinggi adalah laptop Toshiba Satellite C55 dan hasil terendah adalah laptop Acer Aspire E1-470.
\end{abstract}

Kata Kunci: Metode Weighted Product, Pemilihan Laptop, Penunjang Keputusan

\begin{abstract}
Consumers when buying a laptop usually aims just to do school or office work, mostly just to type reports or find information via the internet. The market in Indonesia is very large, so that various brands and types of laptops available today are sold at varied and competitive prices, so potential buyers are even more confused about buying. Most buyers, buy laptops with specifications that are not adapted for their use. The approach used to solve the problem uses the Weighted Product method. This study aims to assist consumers in choosing a laptop through predetermined criteria. The results of the calculation of the selection of laptops with the weighted product method obtained with the highest value is the Toshiba Satellite C55 laptop and the lowest result is the Acer Aspire E1-470 laptop.
\end{abstract}

Keywords: Weighted Product Method, Laptop Selection, Decision Support

\section{PENDAHULUAN}

Pesatnya pasar laptop membuat para produsen saling berebut untuk menjadi pemimpin pasar laptop. Dengan munculnya berbagai kompetitor membuat produsen berlomba-lomba memberikan produk terbaik kepada konsumen melalui produk yang mereka tawarkan, sehingga menimbulkan persaingan yang lebih kompetitif. Biasanya konsumen membeli laptop hanya sekedar mengerjakan pekerjaan sekolah atau kantor yang sebagian besar hanya untuk mengetik laporan atau mencari informasi lewat internet, dengan kebutuan yang ada kita bisa membeli laptop yang berspesifikasi menengah.

Saat ini berbagai merk dan jenis laptop yang ada pasar Indonesia, dijual dengan harga yang bervariasi dan kompetitif, sehingga para calon pembeli menjadi tambah bingung untuk memilihnya (Khairina, Ivando, \& Maharani, 2016),
(Saputra, Sari, \& Mesran, 2017), dan kesulitan dalam menentukan pilihan (N. Syafitri, Syafitri, Sutardi, \& Dewi, 2016) yang sesuai dengan kebutuhannya. Banyak juga para pembeli, membeli laptop dengan spesifikasi yang tidak disesuaikan dengan kegunaannya (N. Syafitri et al., 2016). Terkadang konsumen, tentunya terkadang kita kesulitan dalam memilih laptop disesuaikan dengan anggaran yang ada.

Sesuai dengan permasalahan yang sudah dikemukakan diatas, pada penelitian yang penulis lakukan, menggunakan metode Weighted Product (WP), dikarenakan berdasarkan penelitian sebelumnya, yang dilakukan oleh Syafitri (2016), memberikan solusi dari 5 (lima) laptop (N. A. Syafitri, Sutardi, \& Dewi, 2016) yang menjadi pilihan didapatkan akurasi yang baik dengan metode WP tersebut. Begitu juga penelitian oleh Rani (2014) dengan pemilihan sepeda motor 
dengan metode WP, menghasilkan hasil yang baik dalam pemilihan sepeda motor (Rani, 2014).

Ruang lingkup pembahasannya dimulai dari menentukan kriteria yang dipakai dalam penelitian ini adalah harga, jenis processor, kapasias RAM, hardisk, dan VGA (Video Graphics Accelerator), menentukan alternatif berupa laptop dengan beberapa merk, dan sistem ini akan menghasilkan penilaian pemilihan laptop yang nantinya akan menghasilkan ranking dari nilai terbesar ke terkecil. Tujuan penelitian ini untuk membantu konsumen dalam pemilihan laptop melalui kriteriakriteria yang telah ditentukan. Adanya sistem pendukung keputusan dengan metode weighted product ini konsumen dapat memilih laptop yang sesuai dengan kebutuhan.

\section{METODE PENELITIAN}

Penelitian ini kriteria yang digunakan sebanyak 5 (lima) kriteria, yaitu :

a. Harga

Pada dasarnya adalah sebagai tolak ukur terpenting bagi sebagian besar calon pembeli.

b. RAM (Random Access Memory)

Sebagai media penyimpanan temporer dalam sebuah computer, menjadi pertimbangan penting, dikarenakan RAM sangat mempengaruhi kinerja dari sebuah computer. Semakin besar kapasitas dan seamakin tinggi kecepatan dari RAM sebuah laptop, semakin bagus dan cepat pula kinerja laptop tersebut.

c. Processor

Sebagai otak dari komputer merupakan salah satu pertimbangan penting dalam pemilihan laptop. Processor dengan kecepatan yang inggi mempu memproses dan melakukan perhitungan dengan cepat pula.

d. Hardisk

Sebagai media penyimpanan semi-permanen menjadi pertimbangn penting, dimana semakin besar kapasitas harddisk sebuah laptop, semakin banyak pula data-data yang bisa disimpan oleh penggunanya.

e. VGA (Video Graphics Accelerator)

Sebagai pengolah data grafis dalam sebuah laptop menjadi pertimbangan penting, khususnya bagi calon pembeli laptop yang bertujuan untuk menggunakan laptopnya sebagai media bermain game ataupun sebagai media bekerja yang menggunakan aplikasi-aplikasi multimedia yang berat. Sedangkan untuk alternatif pilihan produk dari toko penjual laptop adalah sebagai berikut :
a. Acer Aspire One Z1402
b. Lenovo S400
c. Toshiba Satellite C55
d. Acer Aspire E1-470

\section{e. Asus S46CB}

Skala pengukuran yang digunakan dalam observasi kepada responden adalah skala likert, dimana akan didapat jawaban berupa sangat setuju, setuju, netral, tidak setuju, dan sangat tidak setuju. Dalam penelitian ini analisa yang digunakan adalah analisis data kuantitatif, karena data yang didapat berupa simbol angka atau bilangan yang dapat menghasilkan suatu kesimpulan yang berlaku di dalam suatu parameter.

\section{Metode Weighted Product (WP)}

Metode Weighted Product menggunakan teknik perkalian untuk menghubungkan ratingattribute, dimana rating tiap atribut harus dipangkatkan terlebih dahulu dengan atribut bobot yang bersangkutan (Kusumadewi, Hartati, Harjoko, \& Wardoyo, 2006). . Dalam penelitian ini akan menggunakan Metode Weighted Product dimana di dalam penentuan sebuah keputusan dengan cara perkalian untuk menghubungkan rating atribut, dimana rating setiap atribut dipangkatkan dulu dengan bobot atribut yang bersangkutan.

Langkah-langkah yang dilakukan dalam penyelesaian masalah menggunakan metode Weighted Product seperti dibawah ini.

\section{Normalisasi atau Perbaikan Bobot}

$W_{j}=\frac{W_{j}}{\sum w_{j}}$

Melakukan normalisasi atau perbaikan bobot untuk menghasilkan nilai $w_{j}=1$ dimana $1,2, \ldots$, $\mathrm{n}$ adalah banyak alternatif dan $\sum w_{j}$ adalah jumlah keseluruhan nilai bobot.

2. Menentukan Nilai Vektor (S)

$S_{i}=\prod_{j-1}^{n} X_{i j} W_{j} \prod_{j-1}^{n} X_{i j} W_{j}$

, dengan $\mathrm{i}=1,2, \ldots, \mathrm{n}$

3. Menentukan nilai vector (S) dengan cara mengalikan seluruh kriteria dengan alternatif hasil normalisasi atau perbaikan bobot yang berpangkat positif untuk kriteria keuntungan (benefit) dan yang berpangkat negatif untuk kriteria biaya (cost). Dimana (S) merupakan preferensi kriteria, $(x)$ merupakan nilai kriteria dan (n) merupakan banyaknya kriteria.

4. Menentukan Nilai Vektor (V)

$V_{i}=\frac{\prod_{j=1}^{n} x_{i j} w_{j}}{\prod_{j=1}^{n}\left(x_{j}^{w}\right) w_{j}}$ 
, dengan $\mathrm{i}=1,2, \ldots, \mathrm{n}$

Menentukan nilai vector (V) dimana vector (V) merupakan preferensi alternatif yang akan digunakan untuk perangkingan dari masing-masing jumlah nilai vector (S) dengan jumlah seluruh nilai vector $(S)$.

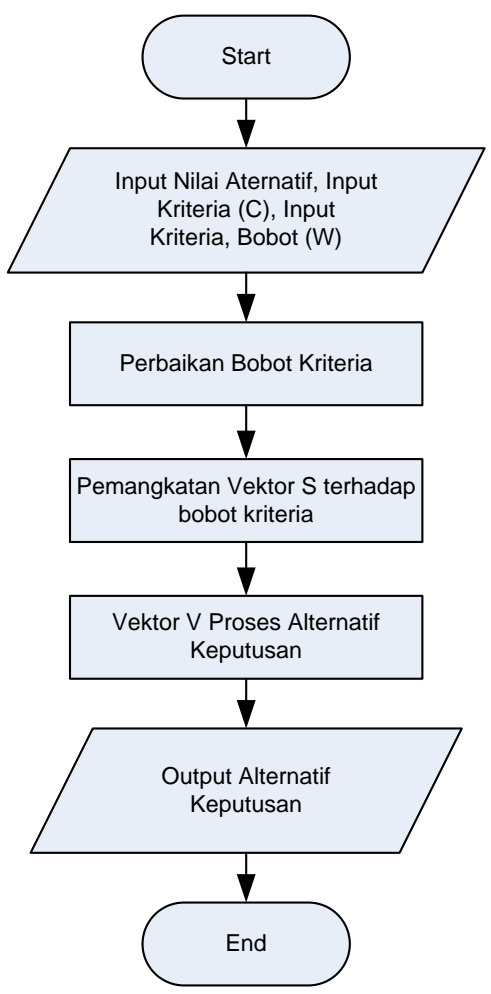

Gambar 1. Algortima Metode Weighted Product

Bobot kriteria tersebut yang dijadikan pengujian didapat dari hasil kuesioner dimana responden memilih tingkat kepentingan sesuai dengan kebutuhan yang sesuai dalam melakukan pemilihan laptop, kemudian dilakukan normalisasi bobot atau perbaikan bobot dengan menentukan vektor $S$ yaitu nilai dari setiap alternatif, perhitungan ini dilakukan dimana data yang akan dikalikan yang sebelumnya dilakukan pemangkatan dengan bobot masing-masing kriteria. Setelah masing-masing vektor $\mathrm{S}$ mendapatkan nilai langkah selanjutnya adalah menentukan nilai vektor $\mathrm{V}$ yang digunakan untuk perangkingan alternatif. Setelah perhitungan menggunakan vektor V selesai, langkah selanjutnya adalah memasukan semua hasil perhitungan ke dalam tabel sesuai nilai tertinggi dari nilai vektor $\mathrm{V}$, maka akan didapatkan hasil perhitungan yang menunjukkan perangkingan nilai vektor $\mathrm{V}$ yang terbesar hingga terkecil, sehingga didapat alternatif terbaik rekomendasi pemilihan laptop berdasarkan nilai tertinggi vektor $\mathrm{V}$.

\section{HASIL DAN PEMBAHASAN}

\section{A. Data Penelitian}

Pada tahap ini penulis mengumpulkan data pemilihan laptop yang diperlukan dalam melakukan perhitungan menggunakan metode weighted product. Berikut ini adalah kriteria yang dijadikan acuan dalam memilih laptop dengan menggunakan metode weighted product.

Tabel 1. Kriteria

\begin{tabular}{cc}
\hline Kriteria & Simbol \\
\hline Harga & $\mathrm{C} 1$ \\
RAM & $\mathrm{C} 2$ \\
Processor & $\mathrm{C} 3$ \\
Hardisk & $\mathrm{C} 4$ \\
VGA & $\mathrm{C} 5$ \\
\hline
\end{tabular}

Dari tabel tersebut, maka ditentukan suatu tingkatan kepentingan kriteria berdasarkan nilai bobot pada setiap kriteria dengan nilai bobot 1 sampai dengan 5, pembobotan ini mengacu pada skala likert, yaitu:

Tabel 2. Nilai Bobot

\begin{tabular}{cc}
\hline Pernyataan & Bobot \\
\hline Sangat Tidak Penting & 1 \\
Tidak Penting & 2 \\
Cukup Penting & 3 \\
Penting & 4 \\
Sangat Penting & 5 \\
\hline
\end{tabular}

\section{B. Data Pengujian}

Pada tahap ini akan dilakukan pengujian dengan menggunakan metode weighted product untuk pengolahan data menentukan keputusan pemilihan laptop.

\section{Metode Weighted Product}

Ada beberapa langkah untuk melakukan perhitungan menentukan keputusan pemilihan laptop dengan menggunakan metode weighted product adalah sebagai berikut.

\section{a. Menentukan Alternatif}

Menentukan alternatif yang akan digunakan dalam perhitungan. Pada pengujian ini akan digunakan 5 sampel data laptop.

Tabel 3. Data Laptop

\begin{tabular}{|c|c|c|c|c|c|c|c|}
\hline \multirow{2}{*}{ No } & \multirow{2}{*}{ Laptop } & \multicolumn{5}{|c|}{ Spesifikasi } & \multirow{2}{*}{ Kode } \\
\hline & & Harga & RAM & Processor & HDD & VGA & \\
\hline 1 & $\begin{array}{c}\text { Acer } \\
\text { ASPIRE } \\
\text { One } \\
\text { Z1402 }\end{array}$ & 4.390 .000 & $2 \mathrm{~GB}$ & $\begin{array}{l}\text { Intel Core } \\
\text { i3 }\end{array}$ & $\begin{array}{c}500 \\
\mathrm{~GB}\end{array}$ & $\begin{array}{c}\text { Intel } \\
\text { HD } \\
5.500\end{array}$ & A \\
\hline 2 & $\begin{array}{l}\text { Lenovo } \\
\text { S400 }\end{array}$ & 3.900 .000 & $4 \mathrm{~GB}$ & $\begin{array}{c}\text { Intel Core } \\
\text { i3 }\end{array}$ & $\begin{array}{c}500 \\
\mathrm{~GB}\end{array}$ & $\begin{array}{c}\text { AMD } \\
\text { Radeon } \\
\text { HD } \\
7450\end{array}$ & B \\
\hline 3 & $\begin{array}{l}\text { Toshiba } \\
\text { Satellite }\end{array}$ & 6.390 .000 & $4 \mathrm{~GB}$ & $\begin{array}{c}\text { Intel Core } \\
\text { i3 }\end{array}$ & $1 \mathrm{~TB}$ & $\begin{array}{l}\text { Intel } \\
\text { HD }\end{array}$ & C \\
\hline
\end{tabular}




\begin{tabular}{|c|c|c|c|c|c|c|c|}
\hline \multirow{2}{*}{ No } & \multirow[b]{2}{*}{ Laptop } & \multicolumn{5}{|c|}{ Spesifikasi } & \multirow{2}{*}{ Kode } \\
\hline & & Harga & RAM & Processor & HDD & VGA & \\
\hline & C55 & & & & & 5.500 & \\
\hline 4 & $\begin{array}{c}\text { Acer } \\
\text { Aspire } \\
\text { E1-470 }\end{array}$ & 5.490 .000 & $2 \mathrm{~GB}$ & $\begin{array}{c}\text { Intel Core } \\
\text { i3 }\end{array}$ & $\begin{array}{c}500 \\
\mathrm{~GB}\end{array}$ & $\begin{array}{c}\text { Intel } \\
\text { HD } \\
4000\end{array}$ & D \\
\hline 5 & $\begin{array}{c}\text { Asus } \\
\text { S46CB }\end{array}$ & 7.102 .000 & $4 \mathrm{~GB}$ & $\begin{array}{c}\text { Intel Core } \\
\text { i3 }\end{array}$ & $\begin{array}{c}500 \\
\mathrm{~GB}\end{array}$ & $\begin{array}{l}\text { nVidia } \\
\text { Geforce } \\
\text { GT } 740\end{array}$ & E \\
\hline
\end{tabular}

b. Menentukan Perbaikan Bobot Kriteria

Menetukan bobot preferensi atau menentukan tingkat kepentingan berdasarkan tingkat kepentingan masing-masing kriteria. Berikut adalah nilai bobot yang diberikan oleh responden, yaitu:

Tabel 4. Masukkan Responden

\begin{tabular}{lc}
\hline \multicolumn{1}{c}{ Kriteria } & Nilai \\
\hline Harga & 5 \\
Kapasitas RAM & 3 \\
Jenis Processor & 4 \\
Kapasitas Hardisk & 3 \\
VGA & 2 \\
\hline
\end{tabular}

Selanjutnya akan dilakukan perbaikan bobot terlebih dahulu dengan bobot awal $W=(5,3,4,3$, $2)$, dengan $W$ adalah bobot masing-masing kriteria yang responden berikan. Berikut adalah hasil dari perhitungan perbaikan bobot kriteria.

Tabel 5. Perbaikan Bobot Kriteria

\begin{tabular}{lcc}
\hline \multicolumn{1}{c}{ Kriteria } & Nilai & Bobot \\
\hline Harga & 5 & 0,294 \\
RAM & 3 & 0,176 \\
Processor & 4 & 0,235 \\
Hardisk & 3 & 0,176 \\
VGA & 2 & 0,118 \\
\hline
\end{tabular}

\section{Menentukan Bobot Setiap Alternatif}

Langkah selanjutnya adalah memberikan bobot kriteria untuk masing-masing data laptop yang terdapat pada tabel 3 Data laptop. Berikut adalah bobot kriteria setiap laptop, yaitu

Tabel 6. Bobot kriteria Setiap Laptop

\begin{tabular}{lccccc}
\hline \multirow{2}{*}{ Kriteria } & \multicolumn{5}{c}{ Alternatif } \\
\cline { 2 - 6 } & A & B & C & D & E \\
\hline Harga & 4 & 5 & 3 & 4 & 3 \\
RAM & 1 & 2 & 2 & 1 & 2 \\
Processor & 5 & 5 & 5 & 5 & 5 \\
Hardisk & 3 & 3 & 5 & 3 & 3 \\
VGA & 3 & 3 & 3 & 2 & 5 \\
\hline
\end{tabular}

\section{Menghitung Vector S}

Setelah mendapatkan perhitungan nilai perbaikan bobot kriteria, maka langkah berikutnya adalah menghitung vector S dimana perhitungan ini akan dikalikan tetapi sebelumnya dilakukan pemangkatan dengan bobot masing-masing kriteria. dengan bobot sebagai pangkat positif untuk kriteria yang menguntungkan dan bobot negatif untuk kriteria biaya. Berikut adalah hasil dari perhitungan vector $\mathrm{S}$, yaitu:

Tabel 7. Perhitungan vector S

\begin{tabular}{cc} 
Alternatif & Bobot \\
\hline A & 1,339 \\
B & 1,417 \\
C & 1,798 \\
D & 1,276 \\
E & 1,746 \\
\hline
\end{tabular}

\section{Menentukan Vector V}

Setelah mendapatkan nilai vector $\mathrm{S}$, langkah selanjutnya adalah menentukan perangkingan alternatif laptop dengan cara membagi nilai vector $\mathrm{V}$ yang digunakan untuk perankingan bagi setiap alternatif dengan nilai total dari semua nilai alternatif vector S. Setelah perhitungan menggunakan vector $\mathrm{V}$ selesai, langkah selanjutnya adalah memasukkan semua hasil perhitungan ke dalam table sesuai nilai tertinggi dari vector $\mathrm{V}$, maka akan didapat nilai tertinggi sebagai nilai rekomendasi.

Tabel 8. Nilai Hasil

\begin{tabular}{cc}
\hline Alternatif & Nilai \\
\hline A & 0,176 \\
B & 0,187 \\
C & 0,237 \\
D & 0,168 \\
E & 0,230 \\
\hline
\end{tabular}

Maka hasil dari perhitungan pemilihan laptop dengan menggunakan metode weighted product menyatakan bahwa nilai tertinggi adalah alternatif C laptop Toshiba Satellite C55, Kedua alternatif E laptop Asus S46CB, Ketiga alternatif B laptop Lenovo S400, Ke empat alternatif A laptop Acer Aspire One Z1402 dan terendah adalah alternatif D laptop Acer Aspire E1-470.

Setelah dilakukan perhitungan secara manual, maka selanjutnya akan dilakukan perhitungan dengan menggunakan microsoft excel. Berikut adalah perhitungan yang telah dilakukan, yaitu

Tabel 9. Perbaikan Bobot Kriteria

\begin{tabular}{|c|c|c|c|c|c|}
\hline Kriteria & Harga & RAM & Prosesor & Hardisk & Vga \\
\hline Cost/Benefit & Cost & Benefit & Benefit & Benefit & Benefit \\
\hline $\begin{array}{l}\text { Bobot } \\
\text { Jumlah }\end{array}$ & 5 & 3 & 4 & 3 & 2 \\
\hline $\begin{array}{l}\text { Bobot } \\
\text { Perbaikan }\end{array}$ & 17 & & & & \\
\hline Bobot & 0,2941 & 0,1765 & 0,23529 & 0,1765 & 0,1176 \\
\hline
\end{tabular}


Pada tabel 9 diatas dapat dilihat bahwa nilai yang dihasilkan dengan menggunakan microsoft excel tidak jauh berbeda dengan hasil yang dilakukan dengan menggunakan perhitungan manual.

Tabel 10. Perhitungan Vector $S$

\begin{tabular}{|c|c|c|c|c|c|c|}
\hline $\begin{array}{l}\text { Alternatif } \\
\text { / Kriteria }\end{array}$ & Harga & RAM & Prosesor & Hardisk & VGA & $\begin{array}{c}\text { Vector } \\
\text { S }\end{array}$ \\
\hline \multicolumn{7}{|l|}{ Acer } \\
\hline $\begin{array}{l}\text { Aspire } \\
\text { one } \\
\text { Z1402 }\end{array}$ & 4 & 1 & 5 & 3 & 3 & 1,34189 \\
\hline $\begin{array}{l}\text { Lenovo } \\
\text { S400 }\end{array}$ & 5 & 2 & 5 & 3 & 3 & 1,42016 \\
\hline $\begin{array}{l}\text { Toshiba } \\
\text { Satellite }\end{array}$ & 3 & 2 & 5 & 5 & 3 & 1,80608 \\
\hline $\begin{array}{l}\text { C55 } \\
\text { Acer }\end{array}$ & & & & & & \\
\hline $\begin{array}{l}\text { Aspire E1 } \\
-470\end{array}$ & 4 & 1 & 5 & 3 & 2 & 1,27938 \\
\hline $\begin{array}{l}\text { Asus } \\
\text { S46CB }\end{array}$ & 3 & 2 & 5 & 3 & 5 & 1,75261 \\
\hline
\end{tabular}

Selanjutnya hasil dari perhitungan vector S hasilnya pun tidak jauh berbeda dengan hasil yang dilakukan dengan perhitungan manual.

Tabel 11. Perhitungan Vector $V$

\begin{tabular}{lr}
\hline Alternatif & Vector V \\
\hline Acer Aspire one Z1402 & 0,1766 \\
Lenovo S400 & 0,1869 \\
Toshiba Satellite C55 & 0,2376 \\
Acer Aspire E1 - 470 & 0,1683 \\
Asus S46CB & 0,2306 \\
\hline
\end{tabular}

Berdasarkan perhitungan dengan Microsoft excel, maka hasil yang didapat sama dengan perhitungan secara manual dimana nilai tertinggi adalah alternatif C laptop Toshiba Satellite C55, Kedua alternatif E laptop Asus S46CB, Ketiga alternatif B laptop Lenovo S400, Ke empat alternatif A laptop Acer Aspire One Z1402 dan terendah adalah alternatif D laptop Acer Aspire E1-470.

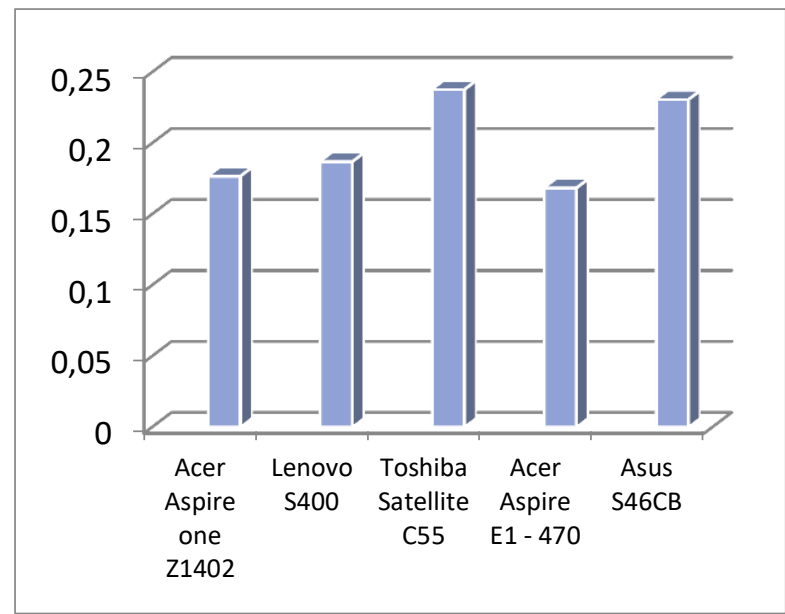

Gambar 1. Grafik Hasil Nilai Perhitungan Weighted Product

\section{KESIMPULAN}

Untuk menggunakan metode weighted product dibutuhkan kriteria yang akan dijadikan pertimbangan, kriteria yang telah ditentukan adalah harga, kapasitas RAM, jenis processor, kapasitas hardisk, dan VGA. Membangun sistem pendukung keputusan pemilihan laptop menggunakan metode weighted product, langkah pertama yang dilakukan adalah menentukan kriteria dan alternatif laptop yang akan dibandingkan, kemudian data terebut akan dihitung dengan menggunakan metode weighted product. Hasil perhitungan pemilihan laptop dengan metode weighted product yang didapat dengan hasil nilai tertinggi adalah laptop Toshiba Satellite C55 dan hasil terendah adalah laptop Acer Aspire E1-470.

\section{DAFTAR REFERENSI}

Khairina, D. M., Ivando, D., \& Maharani, S. (2016). Implementasi Metode Weighted Product Untuk Aplikasi Pemilihan Smartphone Android. Jurnal Infotel, 8(1), 16-23. Retrieved from

http://ejournal.st3telkom.ac.id/index.php/in fotel/article/view/47

Kusumadewi, S., Hartati, S., Harjoko, A., \& Wardoyo, R. (2006). Fuzzy Multi-Attribute Decision Making (Fuzzy MADM). Yogyakarta: Graha Ilmu.

Rani, S. (2014). Sistem Pendukung Keputusan Pemilihan Sepeda Motor Berbasis WEBdengan Metode Weighted Product. Pelita Informatika Budi Darma, 7(3), 62-66.

Saputra, I., Sari, S. I., \& Mesran, M. (2017). PENERAPAN ELIMINATION AND CHOICE TRANSLATION REALITY (ELECTRE) DALAM PENENTUAN KULKAS TERBAIK. KOMIK (Konferensi Nasional Teknologi Informasi Dan Komputer), 1(1), 295-305. https://doi.org/10.30865/KOMIK.V1I1.512

Syafitri, N. A., Sutardi, S., \& Dewi, A. P. (2016). PENERAPAN METODE WEIGHTED PRODUCT DALAM SISTEM PENDUKUNG KEPUTUSAN PEMILIHAN LAPTOP BERBASIS WEB. SemanTIK, 2(1), 169-176. Retrieved from http://ojs.uho.ac.id/index.php/semantik/arti cle/view/762

Syafitri, N., Syafitri, N. A., Sutardi, S., \& Dewi, A. P. 
(2016). PENERAPAN METODE WEIGHTED PRODUCT DALAM SISTEM PENDUKUNG KEPUTUSAN PEMILIHAN LAPTOP BERBASIS WEB. SemanTIK, 2(1), 169-176. Retrieved from

http://ojs.uho.ac.id/index.php/semantik/arti cle/view/762 